\title{
Intermédialités
}

Histoire et théorie des arts, des lettres et des techniques

Intermediality

History and Theory of the Arts, Literature and Technologies

\section{Digital Games for Education: When Meanings Play}

\section{Suzanne de Castell et Jennifer Jenson}

Numéro 9, printemps 2007

Jouer

Playing

URI : https://id.erudit.org/iderudit/1005533ar

DOI : https://doi.org/10.7202/1005533ar

Aller au sommaire du numéro

Éditeur(s)

Centre de recherche sur l'intermédialité

ISSN

1705-8546 (imprimé)

1920-3136 (numérique)

Découvrir la revue

Citer cet article

de Castell, S. \& Jenson, J. (2007). Digital Games for Education: When Meanings Play. Intermédialités / Intermediality, (9), 113-132.

https://doi.org/10.7202/1005533ar
Résumé de l'article

Cet article porte sur le développement d'un jeu éducatif en ligne, Contagion. I tente de montrer comment ce projet nous a menées à une redéfinition théorique de ce que l'on doit considérer comme « éducatif ", et de quelle façon ces questions entretiennent des rapports avec le ludique. À partir du cadre de références fourni par les recherches en éducation fondées sur le design, nous détaillons les différents défis que nous avons rencontrés dans le processus de création de ce jeu alternatif, et comment nous en sommes venues à la conclusion que le contenu du jeu ne se limite pas à son sujet, mais qu'il est lié à et mis en jeu à travers toutes les facettes du jeu. Notre hypothèse est que le contenu, c'est-à-dire sa dimension proprement éducative, traverse tous les aspects relationnels du jeu que le joueur est appelé à rencontrer : choix des personnages, conception visuelle, narration, programmation, objectifs, structure du jeu. 


\title{
Digital Games for Education: When Meanings Play
}

\author{
Suzanne de Castell \\ JENNifER JENSON
}

INTRODUCTION

As the world waits anxiously to witness, not if, but when avian flu makes the jump from bird to human transmission to human to human transmission, and in the meantime millions and millions of domestic flocks are culled world-wide, a small team of students and university-based researchers ${ }^{1}$ are focusing their attention on what an educational game about contagious disease might look like. In the booming first world market of digital games, there has been, in recent years, a corresponding awakening to the possibility of such games for educational ends. Our own work ${ }^{2}$ initially looked to commercial games as representative of and useful models for good design that might be deployed in the making of educationally focused games. We've reviewed in general terms where educational games have tended to steer in directions away from play, pleasure and genuine enjoyment towards curriculum-driven exercises that left less, not more room for playful engagement with ideas than existing print-based educational media.

While by no means the only work on this topic, we do not begin this paper by reviewing the literature in the field: far too few have weighed in on this subject and they are by and large made reference to far too frequently to need to be repeated in detail here. Instead, we document the initial development of an educationally focused web-based game, Contagion, and set out the alternative ways a practical development project has led us to re-theorize our work. With reference

1. The Contagion development team includes, gratefully, Caius Grozov, Nick Taylor, Dawn Mercer, Dima Svetov, Rita Baladi and Nis Bojin.

2. Suzanne de Castell, Jennifer Jenson, "Serious Play," Journal of Curriculum Studies, Vol. 35, No. 6, 2003, p. 649-655. 
to and within the framework of design-based research, we detail here the challenges we encountered designing an alternative game, and how we came to see content, not simply as "what the game is about" but as essentially tied to and enacted through all aspects of the game. We see content, that is, educationally valuable knowledge, as infused through all relational aspects of the game as the activities and doing of things by the player: character selection, art, narrative, programming, goals, game structures and play. We explore each of these in turn to demonstrate how knowledge is constructed through these interrelated elements.

\section{BACKGROUND}

The ability of digital gaming to generate a culture that immerses and absorbs its participants has made it, for those at its borders, an object of new millennial "moral panic." And in many ways, it is threatening. The success of popular culture to initiate a mass audience in patterns and practices of its own consumption has supported the evolution of a hugely powerful entertainment industry reaching into every aspect of our lives. In a global context, digital games are both products and producers of collisions between traditionally disconnected cultural spheres: work and leisure, fact and fiction, home and away, education and entertainment.

Initially widely dismissed as sapping, rather than developing players' intelligence, digital games are increasingly often nowadays researched and studied by educators as sophisticated syntheses of digital sound, image and text which can offer complex strategies, resonant narratives and compelling contextual meanings that engage, sustain, and can develop player attention-and with it, intelligence.

Digital games research has in the past six years become a legitimate field of study, not simply of game design and development, but of player communities, individual game play, the educative potentials of games, and games as an influential popular cultural force-and not just in the lives of young boys. 3 One of the largest new media and digital technology industries, digital gaming offers the richest of immersive environments: games combine increasingly dazzling and sophisticated digital images and sounds, alongside textual communication, to generate virtual worlds in which players must "read" old and new visual, aural, and textual meanings, as part of a playful engagement which is both pleasurable and challenging. As entertainment-oriented commercial gaming continues to advance exponentially in its ability to keep players immersed in digital worlds, knowledge, information, and skill development become increasingly accessible

3. See for example James Paul Gee, What Video Games Have to Teach Us About Learning and Literacy, New York, Palgrave Macmillan, 2003, or Marc Prenksy, Don't Bother Me Mom-I'm Learning, New York, Paragon House Publishers, 2006. 
outside the confines of formal education and training. The challenge of these cultural shifts is that they call for a paradigmatic change of view to reshape and rethink the study of digital games as information-rich cultural texts.

Digital games have the potential to educate in ways that researchers concerned with new digital environments, have yet to capitalize on. In an earlier discussion we've tried to specify some of the kind of research questions and approaches that have been raised by this changed view of digital games for education. ${ }^{4}$ But the approach we take in this paper is one driven by questions that have arisen for us in the very practical work of development of an educational game. This set of questions by no means supposes itself either exhaustive, or even particularly coherent: it should be read as a provisional "coming to terms" with what we have tried to do, the routes we have taken to do that, and what outcomes and challenges we are seeing from the work so far.

\section{CONTAGION: A BRIEF INTRODUCTION}

Contagion is a role-playing adventure game, prototyped in Macromedia Flash for players between the ages of 10-15 and its goal is to develop, through "serious play"5, the health-regarding knowledge, orientations and behaviours necessary for promoting individual and community well-being in the face of four quite different, but equally virulent diseases whose threats to public safety and economic security are currently impacting populations across the demographic spectrum, both locally and globally: Severe Acute Respiratory Syndrome (SARS), West Nile Virus (WNV), Avian Flu, and Acquired Immune Deficiency Syndrome (AIDS). At this time, these viruses can be effectively combated only through the consistent, comprehensive, mass-scale efforts of individuals for whom self-care becomes a permanent, habitual behavioral change. For this reason, education with respect to these conditions and their prevention is an urgent and critical educational requirement.

From a school-based curriculum standpoint, Contagion pursues interdisciplinary subject matters that follow, complement and extend prescribed learning

4. Suzanne de Castell, Jennifer Jenson, "Videogames and Digital Game Play-The New Field of Educational Game Studies," Orbit, Vol. 35, No. 2, 2005, p. 17-19.

5. Lloyd P. Reiber, "Seriously Considering Play: Designing Interactive Learning Environments based on the Blending of Microworlds, Simulations, and Games," Educational Technology Research and Development, Vol. 44, No. 2, 1996, p. 43-58. William E. Blanton, Melanie W. Greene, Michael Cole, "Computer Mediation for Learning and Play," Journal of Adolescent and Adult Literacy, Vol. 43, No. 3, 1999, p. 272-278; Hitendra Pillay, Joanne Brownlee, Lynn Wilss, "Cognition and Recreational Computer Games: Implications for Educational Technology," Journal of Research on Computing in Education, Vol. 32, No. 1, 1999, p. 203-216. 
goals for grades 7-9. ${ }^{6}$ It also emphasizes traditional school subjects and emerging subject fields like technology, biology and medical sciences as well as human and social sciences. But the game is principally intended as a rich interactive career preparation environment, in which students can-and will want to-explore what they need to learn for occupations of interest to them as well as have opportunities to think about, to learn and to "try out" typical working situations which different kinds of professions and occupations might present. The "reward" structure (scoring) in the game is well defined and complex and players are able strategically to experiment with a range of differently weighted goals: economic, scientific, cultural, and social. Character development and experience through game play are recorded and represented in terms of alternative trajectories of possible achievement, for example, knowledge, skill, reputation, tools, and experience. Mobilizing gaming's established culture and commerce, Contagion plays on and is indebted to already-developed knowledge and expectations, including graphical conventions, character types and game strategies of commercial games, both in order to benefit from and to acknowledge and exercise players' cultural knowledge and gaming experience.

\section{PRODUCTION AS THEORY AND RESEARCH: DESIGN-BASED DIGITAL GAMES RESEARCH}

A shift in emphasis from reception-oriented to production-based approaches to educational games studies underlies Contagion's development.7 Similar to "design-based research" in general, and more specifically, the work of designer-

6. Specific instances for the province of Ontario's curricular expectations include Grade 7 Science and Technology: "Life Systems," Grade 8 Geography: "Patterns in Human Geography," Grade 9 Canadian and World Studies: "Social, Economic, and Political Structures," Grade 9 Health and Physical Education: "Healthy Living." Specific curricular expectations in the province of British Columbia include Grade 7 Life Science: "Ecosystems," Grade 8 Science and Technology: "Life Science," Grade 8 and 9 Health and Career Education: "Healthy Living," and Grade 8 and 9 Information and Communications Technology: "Foundations."

7. It is educationally significant that the actual work of production is being done by students at Seneca College and at York and Simon Fraser Universities, so that integral to this project is that it has been working well as a vehicle for education, for skill-development and to enrich, direct and extend the general curriculum these students receive within their different subject areas, from computing to humanities. For a related discussion see Michael Katchabaw, Derek Elliott, Stephen Danton, "Neomancer: An Exercise in Interdisciplinary Academic Game Development," Proceedings of DiGRA 2005 Conference: Changing Views-Worlds in Play, Vancouver, British Columbia, June 2005, http:// www.digra.org/dl/db/o6275.08442.pdf. 
researchers Mateas and $\operatorname{Stern}^{8}$ and colleagues, the Contagion project hopes to engineer innovative conditions for studying educational games, by moving intentionally outside the constraints of existing models for game design. ${ }^{9}$ Methodologically, production-based approaches to inquiry in educational games studies are perhaps not fully an alternative to playing and studying existing games, (LN, p. 299) however building games outside these theories, concepts and models appears to pay an indispensable role in advancing games research and scholarship: as Mateus and Stern put it "building games [...] allows us to experiment with some of the more vexing questions in game studies [...]." ${ }^{10}$ (LN, p. 300)

The Contagion project's specific questions about educational uses of digital games are focused on gender, play and attention, as seen from the perspectives of "situated" technology/technical knowledge, and user-based design. The goal of imparting information is not only mobilized within the game space but also becomes an orientation to action beyond the game. This is a kind of push-pull reciprocal relationship, as the game's architecture structures play possibilities and as such, as Mateas and Stern explain, it becomes a design resource, wherein the game AI "provides the language for thinking about game behaviour [...] the medium within which the designer writes the game by providing authorial resources that support the designer in expressing her design intentions." (LN, p. 308)

Approaching our design of the game as central to our research about educational games has led to our experimentation with designing a very different kind of game than is currently commercially or otherwise available. This process

8. Michael Mateas, Andrew Stern, "Build It to Understand It: Ludology Meets Narratology in Game Design Space," Proceedings of DiGRA 2005 Conference: Changing Views - Worlds in Play, Vancouver, British Columbia, June 2005, p. 299-310. Henceforth, references to this text will be indicated by the initials "LN," followed by the page numbers, and placed between parentheses in the body of the text.

9. Working in this way means engaging with what have been labeled "wicked problems" (see Horst W. J. Rittel, Melvin M. Weber, "Dilemmas in a General Theory of Planning," Policy Sciences, Amsterdam, Vol. 4, 1973, p. 155-159, and LN, p. 305-307). Wicked problems are protean, changing their character as solutions are broached, so that "[...] you do not really understand what problem you were attempting to solve until you have a solution." (LN, p. 306)

10. Their own paper pays considerable attention to the foundational "ludology/narratology" debate in games studies, as an example of how design-based work might help "the field to avoid making taxonomic and prescriptive errors." Ours is similar: a longstanding feud between education and entertainment has impeded the development of educational technologies, and has retarded for too long curricular and pedagogical practices education in its "schooled" incarnation more generally. We are interested in ways to bring learning and play back together, and digital games as new tools for bridging between the two. 
has not been without tension, miscommunication and misunderstandings, but over our two-year development cycle, we have worked with seven undergraduate student artists, three undergraduate student programmers and two graduate students, who have all contributed significantly to the game. Very literally then, these students have been educated by working on the game and we think it is not insignificant that this process has provided an educational context, support and membership in a community that without this kind of funding and opportunity would not otherwise be available. In the following sections, we detail our design elements in relation to their contribution to and representation of knowledge within the game in an effort to show its interrelated and productive significance to what is recognized as (pedantically) "content."

Design-based games research and the challenge of "Baggage-handling"

Creating custom-built "languages" for exploring new territories in games research as well as for perceiving old problems from a new standpoint makes design-based games research an effective means of handling the kinds of "baggage" (at all levels from artificial intelligence through mechanics to character and plot, and even to a game's purposes, functions and uses). To change our thinking, we need sometimes to change the tools with which we do that thinking: it is worth remembering here, from an educational standpoint, that the major impediment to educators taking play seriously and exploring what games can and already do offer to education is the persistence of the assumption, well borne out by the marketplace and a sensation-hungry media, that Grand Theft Auto is "the only game in town," that is, that computer games are about high-speed shooting, killing, the melee, destruction, and havoc. The push-pull of ground-up development means we are more "free" to play, as designers/researchers, with ideas and to make specifically what we want to see tried, to see how it works, not limited to someone else's designs. Not every game needs its flaming sword; not all need be

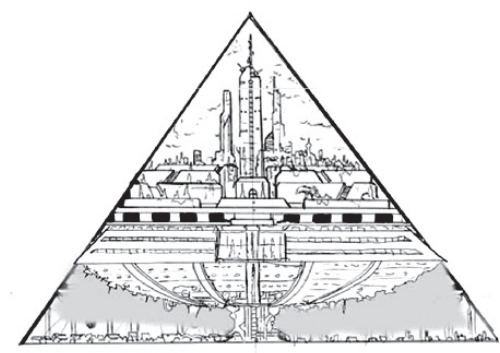

Fig. 1. Pyramidea: Contagion Game Art, Nathan Gaul, 2004-2006. 
hemorrhagic. To go back to Mateas and Stern, "Since technical and conceptual problems in the design space are inextricably intertwined, exploring new regions of design space requires architectural exploration through building experimental games." (LN, p. 308)

\section{NARRATIVE AS CONTENT: A FRAMEWORK FOR UNDERSTANDING}

Contagion is set in a futuristic world, Pyramidea; a socially stratified city-state on the verge of a terrible epidemic. As the name would suggest, Pyramidea is a large vertically partitioned city divided into three segments, each of which serves as the home and starting point for one of the game's three main characters. The pyramid itself purposely invokes the metaphor of a socioeconomic hierarchy, setting the stage for the conflicts the players will encounter on their journey through the various layers of the city.

The Pyramidea Inoculation Network (PIN), a government-based organization which physically, as well as politically, separates Upper and Lower Pyramidea, at the start of the game, is beginning to notice the rising tide of sickness sweeping through the socioeconomically disadvantaged neighbourhoods of the lower city. Under PIN's rule, many sick citizens of Lower Pyramidea have simply disappeared, but this is a solution which seems to be increasingly ineffective, both because the citizens have realized that when PIN is around, fellow citizens who have been ill simply disappear, and also because despite PIN's removal strategies, serious illnesses are breaking out with increasing frequency. The introductory sequence of the game sets the scene for playing in this socially stratified world by taking its viewers back to the time of the plague, recalling that problems of contagious disease are deeply historically rooted. This historical locale also hints at the primary "big bad" in the game: ignorance. Ignorance has been and still is the major hurdle in combating contagious disease.

Upon first entering the game, players select one of three possible characters: a physician from Lower Pyramidea, a community health officer (PIN agent), and an eminent medical researcher specializing in infectious diseases, who works out of the "safe" confines of Upper Pyramidea. The narrative begins with the report of another outbreak of a highly contagious life-threatening disease. Simulations draw upon data and events modeled on recent cases to ensure that the game's informational content is factually grounded. The narrative progresses as the players interact within the game, narrative paths vary with each player until he or she stops playing and/or reaches the end game. There, the players are confronted with their game choices, and the narrative arch is reached as things in Pyramidea go radically out of control-riots, outbreaks, and general mayhem have to be contained by the players. 
Embedded in the narrative, then, is the central conflict of the game which is sustained through simply playing within the game-viral, contagious diseases cannot ever fully be controlled. Ignorance, carelessness, state-based surveillance, self-interest and simply being in the wrong place at the wrong time contribute to the spread of disease. Narrative is in action in the game: it is not something that is "added on" or simply delivered, rather it is co-constructed with the player as the game progresses.

\section{GAMEPLAY AND PROGRAMMING}

Players use web-based information and communications software to coordinate efforts to limit the outbreak, identify its most effective critical intervention points, determine the most effective strategy for containment and treatment of those affected and devise and publicize effective prevention education and public health policy. In a game environment that constantly responds (sometimes predictably and sometimes not) to players' efforts to confine outbreaks, players must also contend with an unwieldy and obstructionist city council bent on concealing the facts and underplaying the seriousness of the situation, fearing the economic consequences of a public declaration of "contagion." Scenario planning, critical evaluation of optimal actions (triage), flexibility and the ability responsively to alter priorities and modify actions, recording and mapping actual and projected vectors of infection, coordination of information, and interdisciplinary team-work are among the capabilities required in/developed by game play.

Currently, the prototype of Contagion's gameplay space is rendered through an isometric engine, built by student programmers entirely in Macromedia Flash with artwork generated in 3DS Max and Adobe Photoshop. "Play" involves navigating various isometric environments (using either mouse or arrow keys) and interacting with Pyramidea's citizens through a point and click functionality, which brings up different interfaces and interaction options depending on the particular character/locale/objective. Using Flash means that players can access the game at school without having to download or install anything beyond an accessible and widely-used browser driver. School technological environments are a significant restriction/parameter and ones that have to be worked within, given that students and teachers are frequently unable to accomplish tasks on their computers as they wait for a certified technician to provide necessary passwords for installation or to install new software themselves. However, using Flash imposes serious programming restrictions which greatly affect, among other things, the size of explorable environments, the number of objects a character is able to interact with in a given space, and the actions and behaviours of nonplayer characters (NPC's). Making a tool for use in a very specific environment, 
means we are not free to take advantage of the graphical, computational and architectural affordances of commercial gaming but must instead limit ourselves to the domain of tactics. Accordingly, how best to tack between the constraints of the user environment (technology use in schools), and the restrictions of the chosen technology on gameplay continues to be central to our development discussions.

For the Contagion design team-working within the constraints of Flash's limited computational and architectural vocabulary-this has meant authoring the game as a series of short episodes enacted through tightly-constrained environments, rather than the sorts of large complex spaces found in most commercial adventure/role-playing games. Programming enables and supports the actions and interactions of players within the game, and as such we see it as central to supporting how knowledge is constructed and produced by gameplay.

\section{ART AND ARCHITECTURE: RESISTING STEREOTYPES}

In her book, Gender Inclusive Game Design: Expanding the Market, Sheri Graner Ray moves the discussion of gender and game design back to essentialized categories of difference. Her book's project, she asserts, is to "attempt to understand the difference between males and females, and then look at various ways to apply these differences to the traditional genres that make up the contemporary computer game industry."11 Her project is nothing new, indeed, it was put very much the same way at the Women in Games conference in Dundee, Scotland, in 2005, but what is disappointing is that the argument for gender inclusiveness so often centers around reductionist accounts of femininity and masculinity and attributes them to difference between sexes. So often gender "by design" means the making of video games in pink boxes.

In the late 199os as is now well known, Brenda Laurel and a number of other seasoned design experts determined that girls needed to be marketed to specifically in order for them to buy and play video games. The result was the design of video games (in Laurel's case a series titled "Purple Moon") based on "what girls wanted"-and as it famously turned out, what girls said they wanted wasn't really what they wanted at all.

Following the failure to directly create for and market to girls in the late 1990s, and the single hit success of Barbie Fashion Designer as a game for girls, the next widely touted game girls and women apparently play has been The Sims (Electronic Arts/Maxis, 2000). Not designed particularly for that market,

11. Sheri Graner-Ray, Gender Inclusive Game Design: Expanding the Market, Hingham, Massachusetts, Charles River Media, 2004, p. xvii. 
The Sims did boast a design team that included women (something rare in the industry) and its content-virtually playing "house" with many different "dolls"attracted the largest female audience ever. We have argued elsewhere ${ }^{12}$ that playing to gender-normed desires, activities and pleasures may have an acceptable outcome for the marketplace; however, educational goals are not necessarily well served that way, and we continue to worry that playing house is really not different enough from dressing dolls to offer an educationally defensible approach to the "gender issue" in game design.

In Contagion, therefore, we leave behind Ray's "gender-inclusive" design principles as well as any notion that we can build something "just for girls" and instead approach the design of our game with gender as one of the game's central questions and problems. What this has meant is an ongoing contention with preconceived notions about narrative, content, plot, characterization, and learning as we attempted to script our game. Early on, for example, while writing the game's plot, we encountered primarily stereotypical war-based narratives - contagious disease as a fighting game-where there were potentials for "guns, germs and steel," a sword where there need not be, and fighting when there could have been some other, more widely engaging and significant tension.

We also insisted that each character be played as either male or female, and in our own conversations attempted to use "she" as a default for all of the characters in the game as well as for the player of the game. As we struggled as a design team to dismantle our own preconceived notions of the narratives and inscriptions $^{13}$ for the stock characters we created in the game, this might seem like a banal inversion, but we found ourselves often reverting to the default pronoun "he" in reference to the characters when they needed to be strong or aggressive and when referring to the person playing the game. Indeed, at conferences like the Game Developers Conference or even at academic conferences like the Digital Games Research Association Conference (DiGRA, 2005) we heard players referred to without any hesitation, inversion or irony as categorically and definitively "he." This unproblematized construct of the player as male and our pronoun "slippage" alerted us to our own embedded stereotypes: when strength and wit were called for, or when a generic image of the player was referred to, it was often the case that we called for a he rather than a she.

12. Suzanne de Castell and Mary Bryson, "Re-tooling Play: Dystopia, Dysphoria, and Difference," in Justine Cassell and Henry Jenkins (eds.), From Barbie to Mortal Combat, Cambridge, The MIT Press, 1998, p. 232-261.

13. Sarah Michaels, Richard Sohmer, "Narratives and inscriptions," in Bill Cope \& Mary Kalantzis (eds.), Multiliteracies, London, Routledge Press, 2000. 
In choosing a Flash platform to design the game in, moreover, we turned away early on from scripting the game using one of the available commercial game engines at the time, either NeverWinter Nights or Unreal Tournament, to evade the inherent, "hard-wired" themes of conquest and violence. We wanted very much to move away from these motivational constructs, to conceptualize another kind of tension (in our case, the enduring human struggles with complicity and ignorance) and to think about building a game that hints at violent potentialities but discourages and in fact punishes those actions.

\section{ART}

Some of the more difficult game-based stereotypes we encountered were in regards to the artwork we asked the young artists to produce for the game. Because we determined that players would be able to play from the perspective of three different characters (a public health worker, a health "enforcement" officer and a viral hunter researcher) we also wanted the option for players to choose to play as either a male or female character. When drawing the female characters, artists encountered deeply embedded stereotypes of what those renderings looks like in games. For the public health worker, for example, the first drawing that was produced was of a highly sexualized, "Barbie" type character. (Fig. 2)

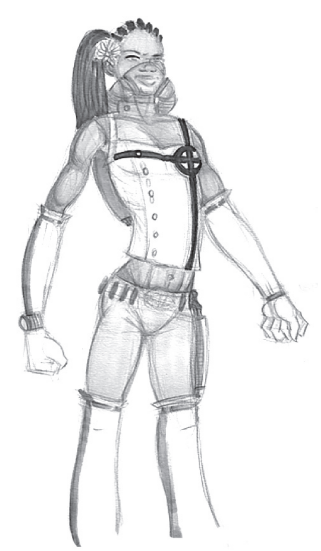

Fig. 2. First draft, Contagion Art Work, Patrick Grimwood, 2004-2006.

The second was a stronger character, but rendered without hair, and looking very much like a victim of contagious disease herself.(Fig. 3) 


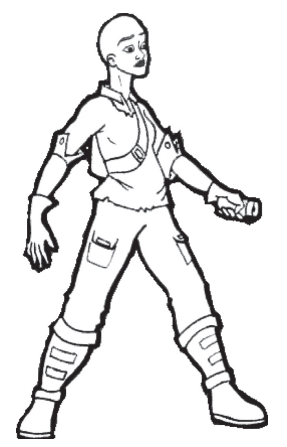

Fig. 3. Second draft, Contagion Art Work, Keith Berry, 2004-2006.

And the third, when we asked for a more likeable character, one a young player might want to "be," was rendered as a slight, visibly fearful, character likely to inspire pity and protection for her vulnerability, rather than confidence in her skill and courage. (Fig. 4) The contrast is marked in relation to her strong, savvy, streetwise male counterpart. (Fig. 5)

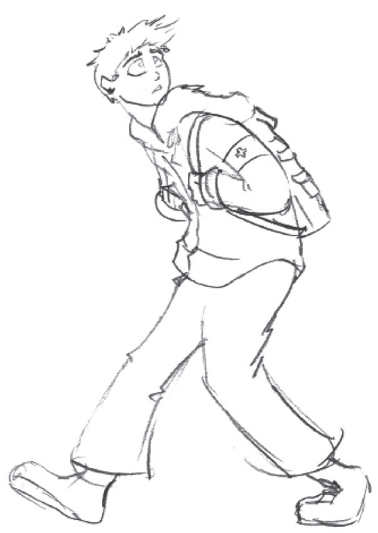

Fig. 4. Draft three, Contagion Art Work, Dan Cox, 2004-2006.

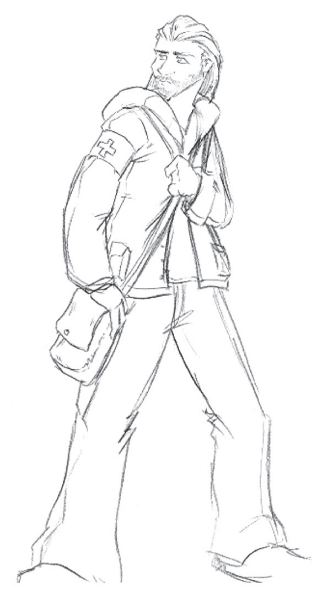

Fig. 5. Final draft, Contagion Art Work, Dan Cox, 2004-2006.

Appealing yet again for a strong engaging and non-stereotyped female street doctor, we got, finally, in this third draft, a young woman with a hip, metropolitan look, now more wary than terrified, who is a bit more welcoming as a character. Note that in this final draft she has a somewhat androgynous look to her.

What we learned from these productions was the difficulty of developing art that did not fall along stereotypical game-design categories. In the end, what we 
constructed was a game that resists the reproduction of highly sexualized female characters and/or highly masculinized male characters. Players interact and play with characters that are still visually appealing without looking like bimbos or buffoons. Here the activities of the player characters and embedded content of the game are mobilized through art.

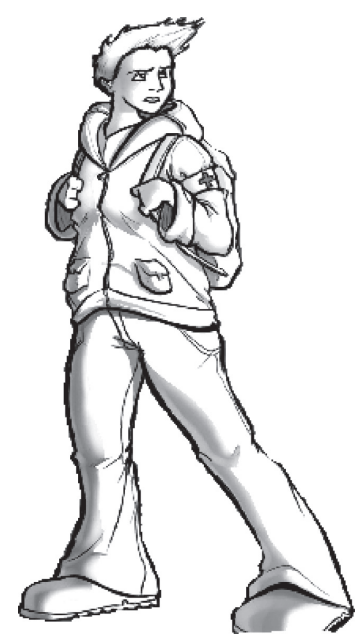

Fig. 6. Final draft, Contagion Art Work, Dan Cox, 2004-2006.

\section{CHARACTER SELECTION}

Then, in the choices we give to our players for the characters they play in the game, we tried to move away from the classically highly sexualized images found in standard RPG's to give character choice in a cartoon-like setting, which permits players a range of color choices to customize their in-game character. We have further given a "marked" male and female character as a choice for each of the three playable characters. Originally, we had wanted to create three androgynous characters and have the players assign gender attributes (or not) to their characters, but our own play testing and previous research suggests that the "default" presumption on androgynous characters was that they were male. As this was not a perception that we wanted to reinforce, we decided to give "marked" sex attributes to our characters, and allow the players to develop them as they will.

Since gender was very much central to our design process, not in terms of figuring out "what girls want," but instead as an ongoing struggle with our own 
presumptions and tendencies to reduce things to simple masculine and feminine binaries, one small achievement has been the reassignment of roles and responsibilities to characters and character-types that are outside the normative hegemonic patriarchal order. As players assume the role of one of the three characters, each embodies and "plays out" a distinct approach to medical/humanitarian crises in dense human populations. Much of the learning which Contagion endeavors to facilitate comes through the players' active exploration of their particular characters' capacities and roles in Pyramidean society, and from seeing the effects of their gameplay choices on individual non-player characters (NPCs) and on Pyramidea as a whole. Upon first logging into the game, players choose from these three characters, select their gender and appearance, rename them, and choose to specialize in an initial two (out of five) attributes: skills, knowledge, street smarts, charisma and tools/technology.

\section{CONTENT DEVELOPMENT AS ACTIVITY STRUCTURES}

Like every other would-be-educational game designer, our Contagion team has spent considerable time mulling over the question of how best to embed content in a game that people would actually choose to play, without being coerced into using it. Like most other would-be-educational game designers, we've been able to generate a few fun and playable sequences in the overall game, activities here and there that a player might actually choose and enjoy. None of these events, activities and moments, however, appears to have much "content" to it. We have, for instance, a driving game, in which Dox, the street/community-based doctor, has been alerted via office computer of outbreaks of illness among citizens trying to get medical help while avoiding the evil PIN agents (who summarily pick up and dispose of anyone who shows signs of infection). Dox's mission involves driving through the streets of lower Pyramidea at night, trying to locate and treat patients identified as needing assistance, while avoiding the patrolling PIN vans, which could apprehend the patients, and confiscate Dox's medical supplies. Kind of fun, for sure. But in the end, it's just another driving game. What's the "content" here? Then there's the pill bottle game, where you "divert resources," to add to Dox's medical supplies. That is, you can add to her dwindling medical supplies by capturing pills rolling down channels at random, avoiding purple and pink pills (which makes lose your supplies) and catching orange and blue pills in a movable pill bottle. Did we want children to learn that pink and purple pills are harmful and orange ones will cure diseases? What exactly could a child learn from playing this game? Then there's a turkey barn game, where poor sick Wattles, the infected wild turkey, gains access to the domestic turkey barn, and 
in her mad dash to get as much food as possible manages to infect a number of domestic birds with avian flu. Did we want children to learn that to get rid of enemy turkeys you have to turn and face them then hit the " $\mathrm{z}$ " key? Or that the way to eat is to walk over shining food pellets?

So: drive and avoid certain cars, catch pills and avoid certain colors, peck at food pellets and fight off domestic turkeys. It begins to look as if the only parts of the game that look like "fun" are the parts with the least educational "content." This way of seeing things suffers from the fatal flaw in most curriculum development, and all instructional design driven by demands of "testing and accountability" to reductive conceptions of learning and knowledge: that learning consists in assimilating items of information capable of being expressed in discreet propositions, whether formulated in linguistic or any other forms of codification. It has now come very nearly to render all other kinds of learning unrecognizable as such. It will perhaps be one of the greater gifts that digital games studies has to offer to education, that this model of "content" is proving grossly unworkable for game designers. Jumping ahead a bit, this is because it is grossly unworkable for education in pretty much all of its forms, game based or not. The real problem is that we in education have not recognized this, so habitual and ubiquitous has the reductionist paradigm become. It's why the age old question: "What did you learn in school today?" is such a stale joke.

For some time now we have imagined, from our very first theoretical explorations of educational gameplay to our last few years actually trying to develop game-based learning resources, that we could avoid the worst excesses of instrumentalist thinking, the sorts of cases where learning goals are crudely and obviously "tacked on" to an otherwise unconnected character, story or activity, by making the learning goals an integral part of the game, its characters and story structures and forms of activity. ${ }^{14}$ But after more than two years of slow development work, it has become clearer that the main problem here is not how to embed content integrally in play. Rather, the problem is with the very idea of "content." Do we really know how to think about content?

\section{GOALS: "NON SCHOOL-BASED TASKS"}

Let's take it from the top: if you wanted someone to learn about current public health crises occasioned by contagious diseases such as HIV, SARS, Avian flu, and West Nile virus, what would you want them to learn? For our own game, we initially identified "self care" as critical in managing these outbreaks, because all of these are viruses for which only self-care ultimately can be effective. Safer sex 
practices, avoiding injection drugs and especially shared needles, using mosquito repellent and monitoring your own living and working areas for stagnant water, using bleach to keep mosquito larvae from developing, avoiding poultry farms and food sources where outbreaks are suspected, washing your hands and wearing masks in high risk areas, all these are practical behaviours of self-care, and none of these make for very engaging play. Nor do lists of signs and symptoms of disease, drugs, and nursing procedures. But think again: do we really learn about self-care by learning these things? When we do change our behaviour, is it because we have learned correct facts of this kind?

It has been sobering for us to look bit by bit at the elements we have built into our game, and see that for any given segment, it is nearly impossible to identify learning goals or outcomes. We have characters, quite engaging ones, we'd argue. We have activities - checking computers for information about outbreaks, getting reports from patients, researching signs and symptoms of the target diseases, as well as driving, pill catching and pecking food and fighting. But where does the learning happen? This question itself is a lot of what is wrong with much educational practice, and not just with educational game design. Many years ago in a philosophical treatise called "The concept of mind," Gilbert Ryle recounted the story of a visitor to Oxford who had asked his host to show him the university. His host took him to the science lab, the lecture theatre, the library, the cafeteria, the student lounge, the soccer field, the bookstore, and the president's office. At the end of several hours of touring, the visitor thanked his host but politely insisted he wanted to see the university. "You've shown me the playing fields, the classrooms the library, all that, but where is the university?" Silly story, yet not so silly for our present purposes. Because of course there is no university apart from these separate things, and all of these things are the university.

Similarly, there is no health education in Contagion apart from its different characters, their different goals, activities and roles, the kinds of conflicts arising between and among them, the difficulties of distinguishing symptoms of Avian flu from West Nile virus from SARS from HIV, the new global panic over migratory birds infecting domestic flocks, the risks of helping people without putting them at greater risk when politics regulates the provision of public health care, and economic realities which mean some people face little or no risk of contagion while others are practically condemned from its onset. And that the bad "boss" in Contagion is not disease or failing to follow medical "rules," it's ignorance. In the graphical frame of the game, self-care is played out beneath the scales of justice, and between twin pillars of ignorance and enlightenment. The graphical frame for the game screen illustrates, on the "ignorance" side, an apocalyptic vision of public health as homeland security, and on the "enlightenment" side, a competing vision of public health as benevolent medical support for 
all. Within an overarching battle against human ignorance, the game and even just the game frame itself, offers the player a view of self-care in which medicalscientific knowledge is just one player on a very crowded field, in which facts play at best a supporting role in what actually happens in the world of human actions to preserve health under conditions of epidemic illness. Games are well-suited to, and in fact call upon, an epistemology very different from that defining curricular knowledge (lesson, test and textbook), changing in turn what knowledge as meaningful "content" in play can mean.

If commercial game designers are victimized by the marketplace, educational game designers are victimized by conceptions of learning and practices of instruction no less crudely instrumentalist. In both cases, values, from social responsibility to critical thinking to aesthetics to pleasure, all fall by the wayside in the face of demands to "show me the money," whether that is strictly monetary in kind, or in some other form of currency. In educational theorizing, the idea that learning consists less in assimilating items of information than in participation in forms of social practice is by now well-established. ${ }^{15}$ But the significance of this powerful reconceptualization of knowledge has been less eagerly picked up on in educational game design, and this, we argue, amounts to a failure to understand that a central impact of changed modes and media for education is the way that transforms, and must transform our very idea of "knowledge." Enough of us are still far too quick to join in the search for identifiable learning outcomes, so we can persuade reluctant parents and teachers that there is much of value in digital game play. To a public now grown accustomed to seeing learning as letters and numbers in boxes next to the names of school subjects, we have to start saying no, this is not what education ever was or could be. This has something to do with politics, with funding, with tests, and with accountability structures among educational stakeholders which "prove" what never so readily can admit of proof: that someone is actually being changed, new thoughts and understandings, dispositions and abilities, new desires and pleasures, insights and talents, are being gradually built up by someone in pursuit of a life worth living.

This, we suggest, is what education is for and about and it's nothing that test scores can ever establish. It means we have to rethink our ideas of what gamebased education can and should look like, and look at things like time invested in playing, care and attention devoted to making and activating a character, choices made and the ethical values they embody, whether and how sacrifices are made which suggest values that sometimes matter more than points accumulated,

15. James Paul Gee, What Video Games Have to Teach Us About Learning and Literacy; Jean Lave and Etienne Wenger, Situated Learning: Legitimate Peripheral Participation, Cambridge, Cambridge University Press, 1991. 
when laughter happens, how players assist one another and what is being understood in those moments, how quickly users can find information needed to get on with the game, how players talk to one another and what kinds of stories they tell and write after playing it.

So, to the critical educational question: what do you learn by pecking enough food pellets and flapping away enough enemy turkeys to stay in the game? You learn to stay in the game. And in staying in the game, you inhabit characters and worlds not your own, deal with crises, escape enemies, understand why incidences of contagion are so frequent in some parts of the world and not in others, see how the same sickness easily treated in one place can be seemingly untreatable in another, realize that humane practices are expensive but just might be worth the costs, recognize the pointlessness of some widely accepted public health strategies, and condemn the mindless inhumanity of routinized culling of healthy animals while refusing to spend money to develop animal vaccines or devise ways to safeguard domestic flocks from infection, find ways to get information, and yes, practice (virtual) hand washing at appropriate times. But these things are not, none of them, "learning goals." The learning goal of any educational game is to stay in a game that invites and enables you to learn and try and be things that everyday life defers, the imaginary and the possible selves, worlds and events that are always potentially "in play" in meanings which circulate around us, but which lived actuality sets aside in its necessary singularity. The learning goal in such a game is simply to play it, to be in that setting, as an active and engaged participant, stringing together the parts, none of which is self-contained, but all of which can be fitted together to make up a richly educative whole.

So seen, even our "mini games" that might initially seem trivially "contentless" serve also, it should be noted, to familiarize novice game players (most typically young girls) with canonical forms of game play-a "shooting" game, a hunt and peck game, a driving game, and a classical kind of puzzle game. Each is representative of a different game genre and as such adds opportunities for the production of (minor) competencies in classic game play forms. This is not insignificant educationally, as it is most typically girls who, while they say they play, don't often have their hands on the controllers and as such are not as confident as their male counterparts with different types of gameplay. ${ }^{16}$

16. Jennifer Jenson, Suzanne de Castell, "Keeping it Real: Gender, Equity and Digital Games," in Jim Terkeurst and Inga Paterson (eds.), Women and Games Conference Proceedings 2005, Dundee, Scotland, University of Abertay Press, 2006, p. 106-115. 


\section{CONCLUSION}

As the school's human subjects, students, teachers and others work increasingly within technologically remediated worlds, the school's fidelity to traditional ways and means of educating becomes correspondingly unsustainable. A new "attentional economy"17 is one important result of the now multi billion-dollar entertainment industry vying for the attention of children and youth. Through the provision of a panoply of new media forms and functions, the idea that attention has value is ubiquitous, and that lesson is not lost on even very young children. Teachers' abilities to "command" children's attention are having to be retooled, in the direction of far greater rhetorical sophistication.

Play occupies a unique position in this new economy, defined as it is by its voluntary nature. In a culture now contending with a shift in conceptions of childhood and adulthood-and a corresponding shift in rights attributions-and peoples' sense of self-worth, of their own sovereignty over much to do with the nature and conduct of their lives, this culture signals for educators a necessary shift in the way human rights, social responsibilities and individual liberties are best regulated in classrooms, as constraint is refigured as increasingly illegitimate. We have to learn to engage students "willingly and wittingly." 8 That means paying attention to occasions where voluntary participation is clearly in evidence. At this time, a primary medium of voluntary attention is digitally-supported gameplay.

Play has been a critically underappreciated resource for learning. For in play, to borrow the words of the philosopher Gilbert Ryle, intelligence is adverbial to attention. This means that whatever a person is paying attention to is where his or her intelligence is at work. Whether you particularly like or respect or understand what that person is attending to, this is where his or her intelligence is being deployed. And nowhere do we see more rapt and immersive attention than in the voluntary activities of play. In education, if this is right so far, it might therefore be time to substitute nominalizations of "play," the noun form in dismissives such as "its just play" which references a "waste of time," and revert in it's place to interrogating the educational worth and significance of play as an active verb, as a reference to the rich kinds of active, inquisitive, and expressive doings that give educational knowledge a place to hang on to, beyond the words which we have for too long misconstrued as the knowledge which they always only incompletely represent, as Plato said, quite some time ago.

17. Jennifer Jenson, Suzanne de Castell, "Keeping it Real."

18. Richard Stanley Peters, The Concept of Education, London, Routledge and Kegan Paul, 1967. 
What we are trying to do in Contagion is to devise an environment which expresses and engages skills, knowledge, critical thinking, ethical dilemmas, character development, and social responsibility, and to engage players voluntarily in paying attention to these many intertwined dimensions of contemporary crises in individual and community health, and the public discourses and practices threaded throughout them.

We are beginning to see as shallow and unproductive the idea of "embedding content," and working instead with presumptions that to the extent that we can engage players' attention, to that extent can we also engage their intelligence. Our job is less to define and demonstrate facts and skills transmitted in the game, than to create a rich, sophisticated, complex and nuanced attentional environment which opens up new horizons, introduces new questions and explores new domains of epistemological and ethical significance, in ways that treat students as intelligent agents in the making of their own lives. 